\title{
Evaluation of Multifunction Bioactivities of Extracted Chitosan and their UV/Ozone Derivatives
}

\author{
Tamer I. M. Ragab ${ }^{1}$, Gehan T. El-Bassyouni², Wafaa A. Helmy ${ }^{1}$, Hanan A. A. Taie ${ }^{3}$, Ahmed Refaat ${ }^{4}$, Medhat A. Ibrahim4, \\ Eman Abd El-Hmeed ${ }^{5}$, Mona A. Esawy ${ }^{{ }^{*}}$ \\ ${ }^{1}$ Chemistry of Natural and Microbial Products Department, Pharmaceutical Industry Division, National Research Centre, 12622 Dokki, Giza, Egypt. \\ ${ }^{2}$ Refractories, Ceramics, and Building Materials Department, Inorganic Chemical Industries and Mineral Resources Division, National Research Centre, \\ 12622 Dokki, Giza, Egypt. \\ ${ }^{3}$ Plant Biochemistry Department, National Research Centre, 12622 Dokki, Giza, Egypt. \\ ${ }^{4}$ Spectroscopy Department, National Research Centre, 12622 Dokki, Giza, Egypt. \\ ${ }^{5}$ Microbial Chemistry Department, National Research Centre, 12622 Dokki, Giza, Egypt.
}

\section{ARTICLE INFO \\ Article history: \\ Received on: 01/05/2018 \\ Accepted on: 09/07/2018 \\ Available online: 31/10/2018}

\section{Key words:}

Chitosan, UV/ozone,

Molecular modeling,

antimicrobial, anticoagulant

and fibrinolytic activity.

\begin{tabular}{l}
\hline ABSTRACT \\
The objective of the present study was the extraction of chitosan from the seashell exoskeleton, then it was \\
modified by the exposure to different time intervals of ultraviolet/ozone (UV/ozone). Also, the study focused on \\
the differentiation between the properties of native chitosan and their UV/ozone forms. The molecular weight and \\
degree of deacetylation of the extracted chitosan were determined. UV/ozone modified chitosan was analyzed using \\
FTIR. The result proved that the irradiation of the prepared samples resulted in slight shifts in the absorbance bands \\
position, also the occurrence of UV-induced photooxidation in the range of $\mathrm{OH}$ vibration. Molecular modeling at \\
B3LYP/6-31g(d, p) and PM6 levels indicated that radiation was supposed to affect the $\mathrm{H}$-bonding of the $\mathrm{NH}_{2}$ group \\
through weak interaction with the six-respective hydrogen bonding in the three $\mathrm{NH}_{2}$ groups. UV/ozone chitosan \\
acquired improvement in the antimicrobial activity by an increment of the exposure time against different pathogen \\
with variable degrees. Antioxidant activity was determined using different methods and the results confirmed the role \\
of UV/ozone in improving this property. The fibrinolytic activity reported that chitosan treated with UV/ozone for 3 \\
and 4 h showed great activity. On the other hand, the anticoagulant activity was non-significant.
\end{tabular}

\section{INTRODUCTION}

Chitosan is a cationic linear polysaccharide containing randomly dispersed $\beta$-(1-4)-linked D-glucosamine and N-acetylD-glucosamine and it is prepared commercially by chitin deacetylation. Evaluation of the degree of deacetylation (DDA) is important for the determination of their chemical content, possessions and structure-properties relationship. Also, a lot of properties could be expected from the knowledge of the DDA value. In general, the chemical characteristics and functional properties of chitosan varied as demanded particular applications;

*Corresponding Author

Mona A. Esawy, Chemistry of Natural and Microbial Products

Department, Pharmaceutical Industry Division, National Research

Centre, 12622 Dokki, Giza, Egypt.

E-mail:mona_esawy@hotmail.com the DDA and the molecular weight (MW) are considered the most important factors affecting the chitosan bioactivity (Zajạc et al., 2015). In the medical field, chitosan has been evaluated for several applications. For instance, chitosan as a glucosamine polymer has been positively applied in biomaterials and drug delivery systems. Also, it had multiple applications in food additives, wastewater treatment, and maintenances for cells, enzymes, and catalysts. As a result of its low toxicity, biocompatibility, and biodegradability, chitosan has different bioactivity such as antimicrobial, antioxidant and anticoagulant agents (MorenoVásqueza et al., 2017; Wassel et al., 2017). It was motivating that chitosan showed an antimicrobial activity against bacteria, fungi, and yeasts. Chitosan as an antioxidant additive had been mentioned in a lot of research work. This property could be acquired from the capacity of this polymer to interact with free radicals through ionic interactions with its amino groups. Also, 
such important properties as biocompatibility, mucoadhesion, hemostatic, analgesic, adsorption enhancing, anti-cholesterol emic and antioxidant strongly depend on the DDA value (Zajạc et al., 2015). UV/ozone modification is useful as it is applicable to an extensive range of organic substrates with little or no pretreatment. Both the physicochemical and topographical effects of UV/ozone treatment may affect the spatial organization of cells. Consequently, biological effects of UV/ozone are greater than simple heating effects, and many practical applications derived from its interactions with organic molecules. Multifunction property of chitosan encourages the researchers to put it in different forms by chemical modifications or UV exposure aiming to improve their biological activities from the point that wavelength ultraviolet radiation could causechemical reactionsand causes change in chemical structure (Ferrero, 2015). High energy of UV radiation results in the destruction of the chitosan matrix. Photodegradation mechanism led to the carboxylic groups' formation in the presence of oxygen. Increasing of irradiation time led to more chitosan degradation (Sionkowska et al., 2014).

Photooxidation is a process that samples undergo when exposed to UV rays in the presence of oxygen. During this process, oxygen atoms are embedded in the polymeric chains resulting in new oxygen-containing groups and, in the case of chitosan, might cause irregular changes in the range of $\mathrm{OH}$ vibration (Kowalonek, 2017a). In 2009, Zainal et al. first introduced $\mathrm{TiO}_{2}-$ Chitosan/Glass photocatalyst, using it in the photodegradation of methyl orange under the illumination of visible light. The removal efficiency was attributed to the reactive $-\mathrm{NH}_{2},-\mathrm{OH}$, and metal oxide contents of the composite that were confirmed by FTIR. In 2010, Nawi et al. reported the vulnerability of chitosan to photooxidation. They recognized that exposing chitosan to UV light altered not only its chemical structure but also its optical properties, extending its spectral response to higher wavelengths. Chitosan's susceptibility to photooxidation together with its adsorptive capacity helped them create a bilayer system by incorporating chitosan with $\mathrm{TiO}_{2}$ for the removal of Reactive Red 4 anionic dye. In 2012, Jawad and Nawi successfully achieved photooxidation of crosslinked chitosan-epichlorohydrin (CS-ECH) film with UV for phenol removal via an immobilized $\mathrm{TiO}_{2} / \mathrm{CS}-\mathrm{ECH}$ photocatalyst system on a glass plate.

The present work focused on chitosan preparation from shrimp's exoskeleton waste. UV/ozone irradiation was done at different time intervals. The molecular structure of chitosan was studied with FTIR spectroscopy. Then for the first time, the change in the UV/ozone chitosan electronic properties was determined by molecular modeling at B3LYP/6-31 g (d, p) and PM6 respectively. Bioactivity studies were performed such as antimicrobial, antioxidant, anticoagulant and fibrinolytic activities. To our knowledge, no sufficient study was done in the fibrinolytic and anticoagulant activity of chitosan or its irradiated form.

\section{MATERIALS AND METHODS}

\section{Chemicals}

2,2-Diphenyl-1-picrylhydrazyl (DPPH), TPTZ (2,4,6-tripyridyl-s-triazine), potassium ferricyanide, Trolox (6-hydroxy-2,5,7,8-tetramethylchroman-2-carboxylic acid) and butylated hydroxyl toluene (BHT) were purchased from Sigma
Chemical Company (St. Louis, MO, USA). All other used chemicals including the solvents were of analytical grade used without any further purification.

\section{Chitosan extraction from exoskeleton wastes}

Shrimps wastes were collected from the local seafood market in Cairo. The collected shrimp exoskeletons wastes were cleaned using tap water then milled using mortar pastel. Chitosan was extracted from shrimp shells according to the modified method (Toan, 2009). The process of extraction involved three steps: (a) removal of calcium carbonate from the shells using 3\% $\mathrm{HCl}(1: 5 \mathrm{w} / \mathrm{v})$, protein and other pigments leaving simply the chitin; (b) purified chitin was dried at $60^{\circ} \mathrm{C}$ until it became crispy and (c) chitin flakes were grounded into small particle in order to facilitate the process of deacetylation. Removal of acetyl groups $\left(\mathrm{CH}_{3} \mathrm{CO}\right)$ from chitin $\left(\mathrm{C}_{8} \mathrm{H}_{13} \mathrm{O}_{5} \mathrm{~N}\right)_{n}$ was experimented using $50 \%$ of $\mathrm{NaOH}$ solution at $65^{\circ} \mathrm{C}$, overnight at a solid to solvent ratio of 1:10 (w/v). The residues were washed using distilled water until neutral $\mathrm{pH}$ was reached. Finally, the resulting chitosan was dried in an oven at $70^{\circ} \mathrm{C}$.

\section{Physicochemical and functional properties characterization}

\section{Moisture and ash contents}

The gravimetric method was used to determine the moisture content while ash content was governed using the standard method (Michael et al., 2004).

\section{Determination of $D D A$}

DDA was measured using a modified acid-base titration method. In brief, chitosan $(0.1 \mathrm{~g})$ was dissolved in $30 \mathrm{ml} \mathrm{HCl}$ $(0.1 \mathrm{~mol} / \mathrm{L})$ at room temperature with the addition of 5-6 drops of methyl orange. The red chitosan solution was titrated using $(0.1$ $\mathrm{mol} / \mathrm{L}$ ) $\mathrm{NaOH}$ solution until it turned into orange (Toan, 2009).

\section{Molecular weight (MW)}

The MW was determined by measuring the intrinsic viscosity. Viscosity measurement of the shrimp shells chitosan was determined using Ubbelohde viscometer. The flow time of both the solution and solvent was recorded in seconds to calculate the intrinsic viscosity $(\eta)$ which was considered as a measure of the MW. The intrinsic viscosity of chitosan was measured using a solvent (0.5 M AcOH-0.2 M NaOAc). It was determined using the Huggins equation (Wang et al., 2004). From the intrinsic viscosity, the MW was determined by employing the classical Mark-Houwink relationship:

$$
[\eta]=\mathrm{KMa}
$$

where $\mathrm{M}$ is viscosity average molecular weight; a and $\mathrm{K}$ are the so-called Mark-Houwink viscometric constants, whose values depend on the degree of acetylation, temperature, and the chosen solvent. For chitosan and the solvent (0.5 M AcOH-0.2 M NaOAc), the constants were $3.50 \times 10^{-4}$ and 0.76 , respectively, despite the deacetylation degree. Five different dilute solutions were used.

\section{UV/ozone treatment}

Shrimp shells chitosan powder was exposed to UV/ ozone for different separable intervals. The UV/ozone unit 
contains a high intensity, low-pressure mercury vapor grid lamp that emits UV light without an outer envelope. UV principally at $184.9 \mathrm{~nm}$ wavelength (LRF 02971, 200 watts and 220 volts) (Poland) excited the molecular oxygen to form atomic oxygen and ozone (AOAC, 2005). In this study, shrimp shells chitosan was oxidized at a distance of $3 \mathrm{~cm}$ from the lamp after preheating the UV lamp for 30 minutes. Exposure to UV/ozone was for few individual episodes of $1 / 4,1 / 2,1,2,3$ and 4 hours.

\section{FTIR studies of chitosan}

Fourier transform infrared spectroscopy (FTIR) was followed to study the variation in the group coordination of chitosan upon the exposure to UV/ozone. The instrument used to record samples' spectra was a Bruker VERTEX 70 Spectrometer. The FTIR spectra of both unexposed and exposed chitosan were obtained using potassium bromide $(\mathrm{KBr})$ pellet method. The spectra were collected between 4000 and $400 \mathrm{~cm}^{-1}$ at room temperature.

\section{Computational details}

All the studied structures were subjected to energy optimization using GAUSSIAN 09 (Gaussian et al., 2010) soft code at Spectroscopy Department, National Research Centre (NRC) Egypt. The structures were calculated using density functional theory (DFT) method with B3LYP (Miehlich et al., 1989; Becke, 1993) using 6-31 g[d,p] basis set. Vibrational spectra were calculated with the same model. SCIGRESS 3.0 molecular modeling software (Stewart, 2009) was utilized at a PM6 semiempirical method to calculate both partial charge and electronegativity.

\section{Biological activities of extracted chitosan}

\section{Antimicrobial activity}

The antimicrobial activity was tested using the good diffusion method. Staphylococcus aureus ATCC 29213, Bacillus cereus, Bacillus subtilis ATCC6633 (Gram-positive), Escherichia coli ATCC 25922, Pseudomonas aeruginosa ATCC27953 (Gramnegative) and Aspergillus Niger (Fungi), Candida albicans NRRL Y-4773 (yeast), Candida tropicalis and Rhizopus. The prepared nutrient agar medium was inoculated with $1 \times 10^{7}$ colony-forming units (CFU) for yeast and fungi. After the media cooled and consequently solidified, wells were made on the agar surface using a $1 \mathrm{~mm}$ cork borer. Using a sterile syringe, $1 \mathrm{mg}$ of the tested compounds was poured into the well. Bacterial plates were incubated at $37^{\circ} \mathrm{C}$ for $24 \mathrm{~h}$ while yeast and fungi at $30^{\circ} \mathrm{C}$ for $72 \mathrm{~h}$. Ciprofloxacin $(50 \mu \mathrm{g})$ and Ketoconazole were, respectively, used as a standard for antibacterial and yeast activity. Zone formation around the wells was observed. The inhibition zone was calculated by measuring its diameter around the well (in $\mathrm{mm}$ ) including the diameter of the well. Readings were carried out in triplicate, in different directions and the average values were tabulated.

\section{Antioxidant activity}

Chitosan samples were dissolved in acetic acid (1\%) and then stirred for $6 \mathrm{~h}$. The methanol solution was used to obtain a known volume.

\section{DPPH free-radical scavenging assay}

The free-radical scavenging activity using the 2,2-diphenyl-1-picrylhydrazyl (DPPH) reagent was determined according to the method described by Brand-Williams (BrandWilliams et al., 1995). The solution of each chitosan treatment $(0.5 \mathrm{~mL})$ was added to $1.0 \mathrm{~mL}$ of freshly prepared ethanolic DPPH solution $\left(20 \mu \mathrm{g} / \mathrm{ml}^{-1}\right)$ followed by stirring. The decolorizing process was recorded after 5 minutes of reaction at $517 \mathrm{~nm}$ and compared with a blank control. All samples were analyzed in triplicate. The ability to scavenge the DPPH radical was calculated using the following equation:

DPPH scavenging activity $(\%)=(($ control absorbance sample absorbance)/control absorbance $) \times 100$

\section{Reducing power assay}

Oyaizu method was used to assess the reducing power of the investigated samples. Then $0.5 \mathrm{~mL}$ solution of each chitosan sample was added to phosphate buffer $(2.5 \mathrm{~mL}, 0.2 \mathrm{M}, \mathrm{pH} 6.6)$ and $1 \%$ potassium ferricyanide $(2.5 \mathrm{~mL})$. The mixture was incubated at $50^{\circ} \mathrm{C}$ for 20 minutes. Aliquots of trichloroacetic acid $(2.5 \mathrm{~mL}$, $10 \%$ ) were added to the mixture and then tracked by centrifugation at $1000 \mathrm{rpm}$ for 10 minutes. The solution upper layer $(2.5 \mathrm{~mL})$ was mixed with distilled water $(2.5 \mathrm{~mL})$ and a freshly prepared ferric chloride $\left(\mathrm{FeCl}_{3}\right)$ solution $(0.5 \mathrm{~mL}, 0.1 \%)$ (Oyaizu, 1986). The intensity of the blue-green color was measured at a wavelength of $700 \mathrm{~nm}$. In this assay, the yellow color of the test solution changed into green depending on the reducing power of the tested specimen. The presence of reductants in the solution initiated the reduction of the ferric/ferricyanide complex into the ferrous form. Therefore, ferrous was monitored by measuring the absorbance at $700 \mathrm{~nm}$. Increased absorbance of their action mixture designated the increment in the reducing power.

\section{Determination of ferric reducing antioxidant power (FRAP)}

According to the method of Benzie and Strain, ferric reducing antioxidant power (FRAP) was assayed (Benzie and Strain, 1996). The stock solutions included $300 \mathrm{mM}$ acetate buffer, pH 3.6, 10 mM of TPTZ (2, 4, 6-tripyridyl-s-triazine) solution in $40 \mathrm{mM} \mathrm{HCl}$, and $20 \mathrm{mM} \mathrm{FeCl}_{3} \cdot 6 \mathrm{H}_{2} \mathrm{O}$ solution. The fresh working solution was prepared by mixing $25 \mathrm{~mL}$ acetate buffer, $2.5 \mathrm{~mL}$ TPTZ solution, and $2.5 \mathrm{~mL} \mathrm{FeCl}_{3} \cdot 6 \mathrm{H}_{2} \mathrm{O}$ solution and then warmed at $37^{\circ} \mathrm{C}$ before being used. The solution of each sample (150 $\mu \mathrm{L}$ ) was allowed to react with $2850 \mu 1$ of the FRAP solution for 30 minutes in dark condition. Readings of the colored product (ferrous-tripyridyltriazine complex) were measured at wavelength of $593 \mathrm{~nm}$. Results were expressed in $\mu \mathrm{mol}$ Trolox/100 $\mathrm{g}$ of the dry matter. Additional dilution was needed if the FRAP value measured was over the linear range of the standard curve.

\section{Anticoagulation activity}

Using the method of USA Pharmacopoeia for the assay of sodium heparin, the anticoagulation activities of all samples were investigated (Oyaizu, 1986). Hard-glass test tubes $(31 \times 100$ $\mathrm{mm}$ ) were cleaned by immersion overnight in chromic acid. To each tube, $0.8 \mathrm{~mL}$ of sample solution $(0.01 \%)$ was added, $0.8 \mathrm{~mL}$ of standard heparin sodium solution (1.4 U.S. P unit/0.8 mL), or 
$0.8 \mathrm{~mL}$ saline solution. To each tube so prepared, $1 \mathrm{~mL}$ of the plasma and $0.2 \mathrm{~mL}$ of calcium chloride solution were added. The tubes were placed in a water bath at $37^{\circ} \mathrm{C}$. Time was immediately recorded and each tube was capped. The time required for clotting was determined.

\section{Evaluation of fibrinolytic activity}

Fibrinolytic activity was performed by exposing a plasma clot to the effect of an aqueous solution by using suitable concentrations. Preparation of the plasma clot was done under the same conditions previously used for determination of anticoagulation activity (US Pharmacopeia of the United State of America 16th Revision, Mack Publishing Company, Washington, DC USA 1960). Sets of three hard-glass test tubes $[31 \times 100 \mathrm{~mm}]$ were cleaned by immersion overnight in chromic acid. To each tube $0.8 \mathrm{~mL}$ saline solution $[0.9 \% \mathrm{w} / \mathrm{v}], 1 \mathrm{~mL}$ plasma and $0.2 \mathrm{~mL}$ calcium chloride solution $(2 \% \mathrm{w} / \mathrm{v})$ were added. After mixing, the tubes were placed in water bath at $37^{\circ} \mathrm{C}$ and when clotting was completed, $1 \mathrm{~mL}$ of Hemoclar [ $2000 \mu \mathrm{g} /$ tube], or the tested sample [2000 $\mu \mathrm{g} / \mathrm{tube}]$ was individually added. The lysis percentage of the plasma clots at $37^{\circ} \mathrm{C}$ was recorded with each sample and compared to standard Hemoclar (Srinivasa Reddy et al., 2015).

\section{Statistical analysis}

Data analysis was carried out with MICROSOFT EXCEL (2007). All data are presented as means \pm standard error of means. The mean of the repeated measurements yields the value for each replicate.

\section{RESULTS AND DISCUSSION}

Chitosan was known as a valuable product due to its multifunction bioactivities. Within this context, the present work focused on the evaluation of chitosan and their different UV/ ozone derivatives properties such as antimicrobial, antioxidant, fibrinolytic and finally anticoagulation activities. Results were interpreted to make a correlation between the properties and the effect of UV/ozone on extracted chitosan.

\section{Chitosan characterization}

\section{Moisture and ash contents}

In the present study, the value of moisture shrimp shell waste was $(72.3 \%)$ which is closely related to that measured by Ushakumari and Ramanujan (71.6\%) (Ushakumari and Ramanujan, 2012). Abdulkarim et al., reported that the moisture content of chitin was inspected to be $8.7 \%$ which is lower than the value for mussel shell (12.9\%) (Abdulkarim et al., 2013). This could be attributed to the source of chitin and the drying conditions. Chitosan had a moisture content of $8.1 \%$ which is almost similar to that of commercial chitosan containing less than $10 \%$ ( $\mathrm{Li}$ et al., 1992). Fresh shrimp shell had $31.33 \%$ ash content, while chitin reported $0.39 \%$ due to the $3 \% \mathrm{HCl}$ effective reduction. In this study, chitosan contained $0.40 \%$ ash. The degree of chitosan solubility and viscosity depends mainly on the ash content; since it should be less than 1\% (Lertsutthiwong et al., 2002). The yield calculated for shrimp waste was $30.11 \%$, which represented chitin $14.20 \%$ and for chitosan $16.31 \%$. The obtained yield was found to be lower than the range reported by Lertsutthiwong (No and Lee,
1995). They revealed that the waste content varied approximately from $45-55 \%$ of the weight of raw shrimp. High yield of extracted chitin resulted from the lower concentration of $\mathrm{HCl}$ could keep shrimp shell minerals and subsequently increased the yield.

\section{$D D A$ and solubility}

In the present study, $50 \%$ of $\mathrm{NaOH}$ concentration was addressed to enhance the deacetylation grade (80.23\%). The DDA was influenced by the $\mathrm{NaOH}$ concentration. Acetyl groups bounded in chitin were difficult to be removed. So, it needed to require a high concentration of $\mathrm{NaOH}$ and temperature. The reaction occurs in two stages under first-order kinetic control. The activation energy for the first step is higher than the second; its value was expected to be $48.76 \mathrm{~kJ} / \mathrm{mL}$ at $25-120^{\circ} \mathrm{C}$ (Ahlafi et al., 2013). The chitosan solubility is one of the important parameters for evaluation of the chitosan quality, where higher solubility will produce a better chitosan. The solubility of chitosan obtained in this study was $97.24 \%$. Temperature and time of deacetylation, alkali concentration, and prior treatments applied to chitin isolation, the ratio of chitin to alkali solution, and particle size were critical factors affecting the chitosan solubility (No and Lee, 1995). The amino group in chitosan had a $\mathrm{pK}$ a value of 6.5 , which led to a protonation in acidic to neutral solution with a charge density dependent on both the $\mathrm{pH}$ and the DDA-value. This makes chitosan water soluble and bio-adhesive which readily binds to negatively charged surfaces (Lim et al., 2015).

\section{Molecular weight}

Chitosan intrinsic viscosity obtained in this study was $13.18 \mathrm{dL} / \mathrm{g}$ which is used to characterize the hydrodynamic properties of chitosan and also to determine the MW using the Mark-Houwink's equation (Wang et al., 1991). In this finding, the molecular weight of extracted chitosan was determined as $1.03 \times$ $10^{6}$ Daltons. The MW of native chitin was usually larger than one million Daltons while commercial chitosan products fall between 100,000 to $1,200,000$ Daltons.

\section{UV/ozone treatment}

Shrimp shells chitosan was subjected to UV/ozone at different time intervals expecting that this way may acquire its new properties and different bioactivities. Previously, it was reported in chitosan irradiation by gamma radiations and it is accounted to be one of the most effective and vastly used methods for improving its antibacterial activity (Bano et al., 2017).

\section{FTIR spectroscopy}

Fig. 1 showed ATR-FTIR chitosan spectrum. The band at $3421 \mathrm{~cm}^{-1}$ is due to the N-H stretching coupled with $\mathrm{O}-\mathrm{H}$ stretching vibrations (You et al., 2009). The bands at wave numbers $2922 \mathrm{~cm}^{-1}$ and $2860 \mathrm{~cm}^{-1}$ were due to $\mathrm{C}-\mathrm{H}$ asymmetric and symmetric stretching vibrations respectively. The band at $1646 \mathrm{~cm}^{-1}$ was corresponding to amide $\mathrm{C}=\mathrm{O}$ stretching (amide I) and that at $1597 \mathrm{~cm}^{-1}$ was corresponding to $\mathrm{N}-\mathrm{H}$ bending (amide II). The bands at 1423 and $1382 \mathrm{~cm}^{-1}$ were assigned to the $\mathrm{CH}_{2}$ and $\mathrm{CH}_{3}$ bending vibrations respectively. The band at $1257 \mathrm{~cm}^{-1}$ was attributed to $\mathrm{C}-\mathrm{O}$ stretching and the band at $1153 \mathrm{~cm}^{-1}$ was ascribed to C-O-C bending. Finally, the band at $1080 \mathrm{~cm}^{-1}$ is typical of $\mathrm{C}-\mathrm{OH}$ stretching vibration. 
Photooxidation is a process that samples undergo when exposed to UV rays in the presence of oxygen. During this process, oxygen atoms are embedded in the polymeric chains resulting in new oxygen-containing groups and, in the case of chitosan, might cause irregular changes in the range of $\mathrm{OH}$ vibration (Kowalonek, 2017a). Chitosan samples subjected to UV/ozone for different time intervals were analyzed using FTIR spectroscopy and spectra were shown in Fig. 2. No new absorption bands can be detected in the spectra of the irradiated samples; however, the positions of the absorption bands shifted only slightly as can be seen in Table 1 (Kowalonek, 2017b; Sionkowska et al., 2010; Ibrahim and Mahmoud, 2009).

Table 1: Bands position in ATR-FTIR spectra of Chitosan before and after UV irradiation.

\begin{tabular}{|c|c|c|c|c|c|c|c|}
\hline Band & Blank & $0.25 \mathrm{hr}$ & $0.5 \mathrm{hr}$ & $1 \mathrm{hr}$ & $2 \mathrm{hr}$ & $3 \mathrm{hr}$ & $4 \mathrm{hr}$ \\
\hline $\mathrm{O}-\mathrm{H}$ stretching & 3421 & 3436 & 3428 & 3436 & 3432 & 3430 & 3421 \\
\hline $\mathrm{C}-\mathrm{H}$ asymmetric stretching & 2922 & 2923 & 2924 & 2923 & 2922 & 2922 & 2922 \\
\hline C-H symmetric stretching & 2860 & 2858 & 2857 & 2864 & 2856 & 2884 & 2882 \\
\hline Amide I & 1646 & 1640 & 1632 & 1644 & 1645 & 1646 & 1645 \\
\hline Amide II & 1597 & 1595 & 1600 & 1600 & 1597 & 1597 & 1598 \\
\hline $\mathrm{CH} 2$ bending & 1423 & 1423 & 1423 & 1423 & 1423 & 1423 & 1423 \\
\hline CH3 bending & 1382 & 1382 & 1383 & 1382 & 1382 & 1382 & 1382 \\
\hline C-O stretching & 1257 & 1257 & 1257 & 1257 & 1256 & 1256 & 1257 \\
\hline $\mathrm{C}-\mathrm{O}-\mathrm{C}$ bending & 1153 & 1154 & 1155 & 1154 & 1154 & 1154 & 1154 \\
\hline C-OH stretching & 1080 & 1089 & 1086 & 1079 & 1088 & 1084 & 1085 \\
\hline
\end{tabular}

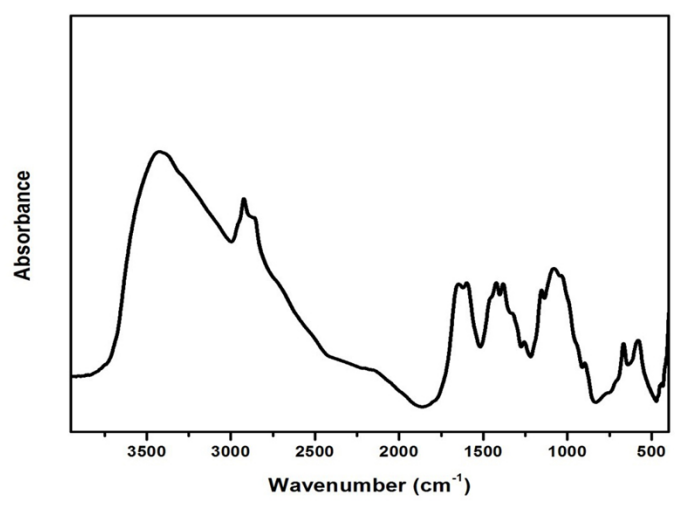

Fig. 1: ATR-FTIR absorption spectrum of chitosan before UV/ozone irradiation.

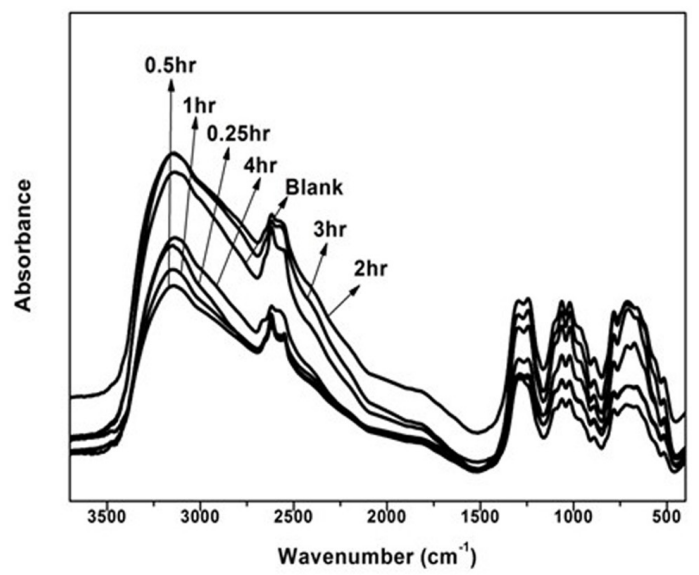

Fig. 2: FTIR absorption spectra of chitosan before and after UV/ozone irradiation.

The absorbance of hydroxyl band in the range of 3000-3600 $\mathrm{cm}^{-1}$ before and after UV irradiation was analyzed in terms of band intensity versus irradiation time as shown in Fig. 3. The intensity of this band was related to the intensity of an internal reference band which was the band originating from $\mathrm{CH}$ asymmetric stretching vibrations at $2922 \mathrm{~cm}^{-1}$ as it is supposed from the obtained spectra that this band was not altered during irradiation. The maxima of the absorption bands of $\mathrm{OH}$ group were normalized in relation to the $\mathrm{CH}$ stretching vibrations (Kowalonek, 2017b). As seen in Fig. 3, during the first 15 min of irradiation, the photooxidation process occurred as the band intensity started to increase probably due to the formation of new hydroxyl/hydroperoxide groups; however, a sharp decrease in the band intensity occurred which may be attributed to the breakdown of the previously formed groups. After $1 \mathrm{hr}$ of irradiation, a significant increase in band intensity due to photooxidation took place, followed by a steady slight increase in band intensity as irradiation continued from 1 up to 4 hours.

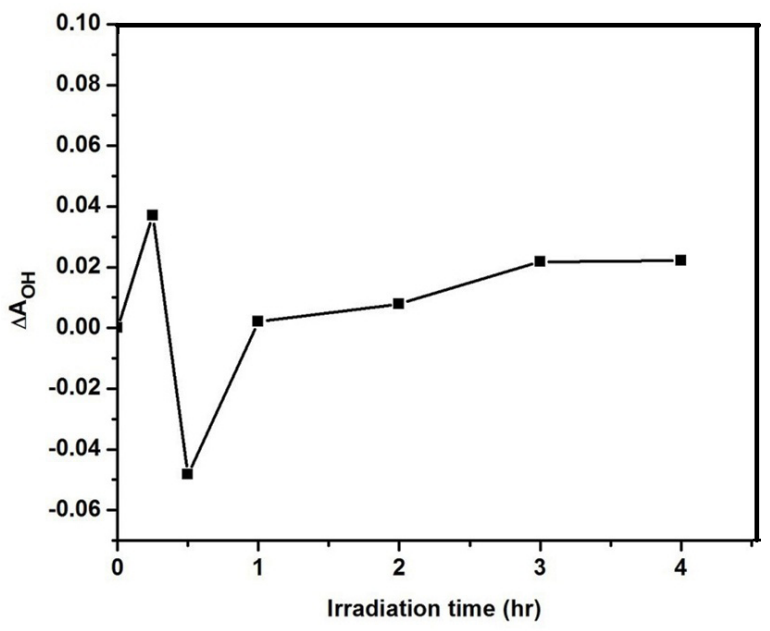

Fig. 3: Changes in the $\mathrm{OH}$ band intensity versus irradiation time. $\Delta \mathrm{A}=\mathrm{A}(\mathrm{t})-$ $\mathrm{A}(0), \mathrm{A}(\mathrm{t} 4)$ - band intensity after UV radiation, A (0) - band intensity before irradiation.

\section{Molecular modeling}

Another way to follow up the change in the structure was throughout molecular modeling which was conducted through electronic structure method using density functional theory at B3LYP/6-31 g(d, p) level. 


\section{Building the model molecules}

A model molecule of chitosan chain consisting of three units together with its atomic numbering was shown in Fig. 4A. It contains two glycosidic rings, one with the amine group and another with the methylamide group. Fifty tow-atomic system gives rise to 150 vibrational degrees of freedom. The radiation effect was supposed to affect the $\mathrm{H}$-bonding of the $\mathrm{NH}_{2}$ group through weak interaction with the 6 respective hydrogen bonding in the
$3 \mathrm{NH}_{2}$ groups. There are 6 models, each one for weak hydrogen bonding as represented in Fig. 4B. The first model represented one weak hydrogen bond while the other 5 bondings were not weak (Fig. 4A). In the last model (Fig. 4B), all the 6 bonding of the $\mathrm{NH}_{2}$ groups were weak bonds. Another model supposed that one hydrogen of $\mathrm{NH}_{2}$ was removed. The models could be describing the radiation effect where weak interaction happened through Van der Waal while another interaction happened through removing one of the hydrogen bonds of the $\mathrm{NH}_{2}$ group of one chitosan unit.

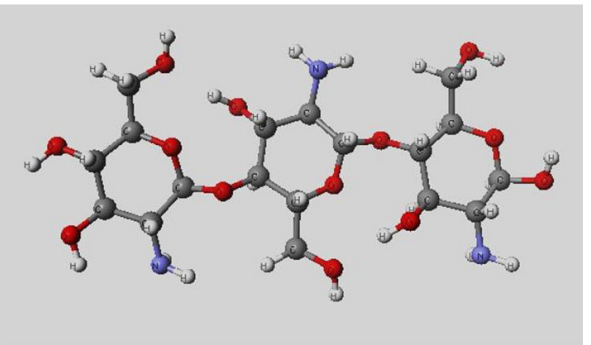

$4 \mathrm{~A}$

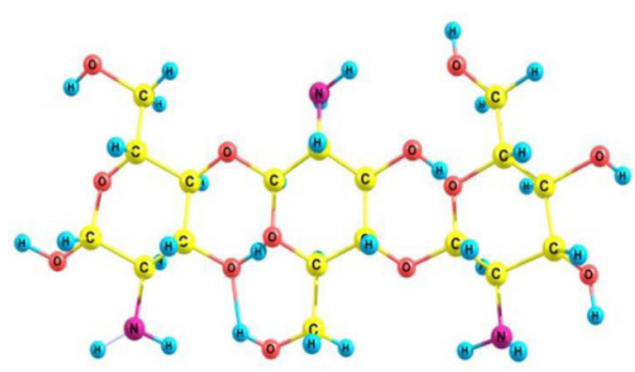

1 weak interaction

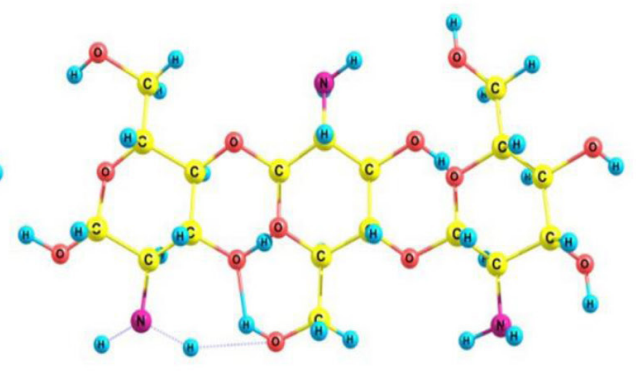

2 weak interactions

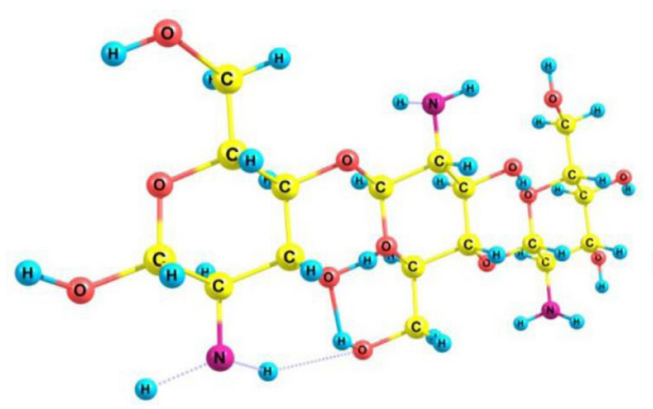

3 weak interactions

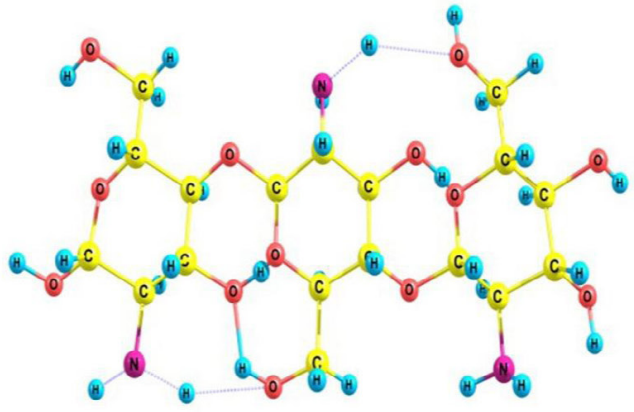

4 weak interactions

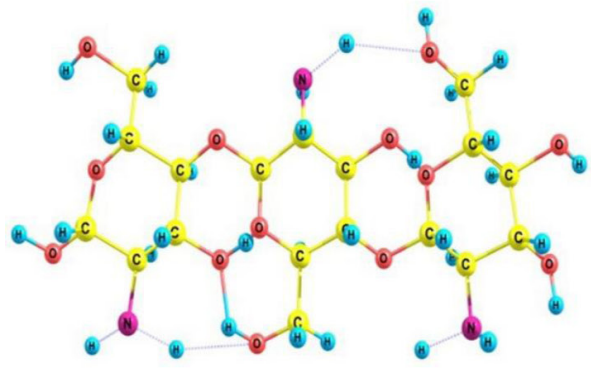

5 weak interactions

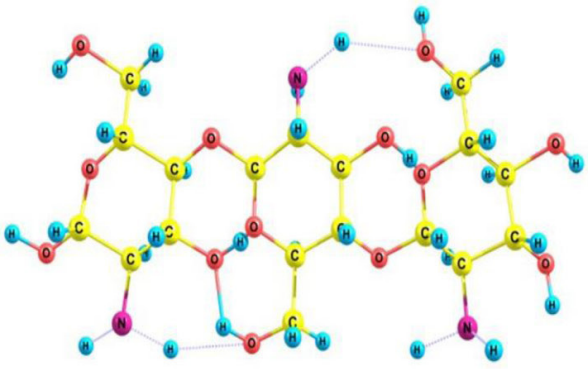

6 weak interactions

Fig. 4: (A) Chitosan model of a molecular structure which consists of three units. (B) Model structure of chitosan three units whereas weak interactions are supposed to take place through Van der Wall interaction as termed in figure 1-6 weak interactions, respectively. 


\section{Calculated parameters}

As noticed from Table 2, the total dipole moment (TDM) for chitosan 3 units was 4.1973 Debye while the HOMO/ LUMO band gap energy was $7.481 \mathrm{eV}$. Weak interaction, even through 6 hydrogen bonds of the three $\mathrm{NH}_{2}$ groups, showed a slight change in TDM and no change in band gap energy (HOMO): Highest Occupied Molecular Orbital, LUMO: Lowest Unoccupied Molecular Orbital and $\Delta \mathrm{E}$ : Band-gap Energy which is the energy difference between the HOMO and LUMO. For model molecule where 1 hydrogen of $\mathrm{NH}_{2}$ group was removed, the TDM is increased to 5.862 Debye while band gap energy was decreased to $4.453 \mathrm{eV}$. It is worth to mention that both TDM and $\mathrm{HOMO} / \mathrm{LUMO}$ band gap energy is considered as a tool to measure the reactivity of a given chemical structure (Ibrahim and Mahmoud, 2009). Increasing the TDM and decreasing band gap energy reflect better interaction with the surrounding molecules. Other parameters which could be an indication for the effect of radiation was partial charge and electronegativity. The partial charge which was also known as the net atomic charge was due to the asymmetric distribution of electrons in a given chemical bond (Heinz and Suter, 2004).

Table 2: Calculated total dipole moment (TDM) as Debye for the studied model molecules at B3LYP/6-31 $\mathrm{g}(\mathrm{d}, \mathrm{p})$ and band gap energy $(\Delta \mathrm{E})$.

\begin{tabular}{ccccccccc}
\hline Parameters & Cs & W1 & W2 & W3 & W4 & W5 & W6 & Cs-1 \\
\hline TDM & 4.1973 & 4.1975 & 4.1976 & 4.1969 & 4.1971 & 4.1976 & 4.1973 & 5.862 \\
$\Delta \mathrm{E}(\mathrm{eV})$ & 7.481 & 7.481 & 7.481 & 7.481 & 7.481 & 7.481 & 7.481 & 4.453 \\
\hline
\end{tabular}

For the case of the studied model molecule, the partial charge could be a tool which is quantifying the degree of ionic versus covalent bonding. It is, in this case, one important tool to describe the effect of radiation upon chitosan. As indicated in Table 2 , there are seven assumptions starting with radiation affecting only 1 bond as Van der Waal up to 6 bonds then remove 1 bond from the $\mathrm{NH}_{2}$. Partial charges for $\mathrm{NH}_{2}$ group are not changed. The change was recorded as far as one hydrogen atom was removed as a result of radiation. Another effect upon the same model molecules is followed through the calculated electronegativity (William, 1996). It could be simply known as a measure of the tendency of a certain atom for attracting a bonding pair of electrons. As illustrated in Table 3, PM6 data indicated that no change in the calculated electronegativity for the Van der Waal interaction was observed. The removed hydrogen recorded its change on $\mathrm{N}$-atom from 0.321 to 0.246 ; this trend was in good agreement with those obtained for partial charge quantum mechanical semi-empirical level of theory. Structures from W1 to W6 stand for Van der Waal interaction for up to 6 hydrogen bonds in the chitosan structure of three units. Cs-1 is the chitosan model molecule with removed hydrogen bonding.

The results of molecular modeling calculations and those of FTIR are in good agreement with each other. In molecular modeling calculations, the effect on the values of TDM, $\Delta \mathrm{E}$, partial charge and electronegativity was the removal of one hydrogen atom as a result of irradiation with UV through the process of photooxidation. This is equivalent to the results obtained by FTIR, where UV irradiation resulted in photooxidation of chitosan which was confirmed by observing the increase in the intensity of $\mathrm{OH}$ group bands probably due to the loss of hydrogen and formation of new hydroxyl/hydroperoxide groups.

\section{Biological activities of chitosan}

\section{Antimicrobial activity}

Previously, chitosan was well known as an antimicrobial against a wide range of microorganisms. The molecular weight (MW) and degree of acetylation (DDA) are the fundamental keys in controlling the antimicrobial effectiveness (Hongpattarakere and Riyaphan, 2008). In this part, the main aim was to evaluate the role of UV/ozone radiation on chitosan antimicrobial property. In this finding, the antimicrobial activity of native chitosan and their different UV/ozone derivatives was tested against different microorganisms (yeast, gram-positive and gramnegative bacteria, and fungi). The results represented in Table 4 pointed out clearly that UV/ozone exposure had a wide degree of variation on antimicrobial effect. In general, the main key controlling the antimicrobial activity was the time of exposure since, in approximately, all tested organisms reported that the antimicrobial activity increased by the elongation of exposure time. Also, the UV/ozone exposure to native chitosan gained it a new antimicrobial activity against Salmonella. A few years ago, irradiation of chitosan by UV took part (Rashid et al., 2012) since, Guirguis et al. (Guirguis et al., 2016) showed that the chitosan exposed to UV/ozone confirmed a high potential of antibacterial activity compared to the native form. In this finding, Zhang et al. thought that $\gamma$-ray irradiation increased the antimicrobial activity of chitosan (CS)/graphene oxide (GO) composite films (Zhang et al., 2018).

\section{Effect of UV/ozone radiation on DPPH free-radical scavenging activity}

The values of the scavenging activity of free radicals by chitosan solutions were shown in Fig. 5A. The figure declared that UV/ozone irradiation increased the antioxidant activity of chitosan using DPPH assay. The activity increased by the upsurge of exposure duration but it started to decline again after two hours of exposure. The highest increment was after one hour, it was found to be $47.54 \pm 0.69 \%$ while the radical scavenging activity of control (zero time) was $29.07 \pm 0.42 \%$ at the same concentration ( $1 \mathrm{mg}$ / $\mathrm{mL})$. This means that the UV exposure for one hour led to about $61.15 \%$ increase more than control. Similar results were obtained by Rashid et al. they reported that the increase of the antioxidant activity as function of gamma irradiation may be related to the reduction of the chitosan $\mathrm{MW}$ and this may be due to the breaking of the acetyl bonds ( $\mathrm{C} 1$ and $\mathrm{C} 4)$ with subsequent formation of new active sites, capable of reacting with highly reactive species such as free radicals (Rashid et al., 2012). Also, the rupture of the amide bond might occur causing a partial deacetylation of the molecule (Gordon, 1990).

\section{Effect of UV/ozone radiation on reducing power ability}

The use of more than one method to measure the antioxidant activity has been recommended for a better 
understanding of the tested antioxidant properties. The reducing properties were generally associated with the presence of reductones, which have been shown to exert antioxidant action by breaking the free radical chain through donating a hydrogen atom (Abd El-Rehim et al., 2012). The reducing power ability of chitosan samples significantly increased (32.35\%) after exposure to UV/ozone irradiation for 15 and $30 \mathrm{~min}$ respectively in comparison to the control at the same concentration $(1 \mathrm{mg} /$ $\mathrm{mL}$ ). Afterward, the increase in exposure time did not show clear differences in reducing power ability (Fig. 5B). On the other hand, Abd El-Rehim et al., concluded that the reducing power of irradiated chitosan increased significantly with increasing the dose of irradiation as well as their concentrations, and this may be accredited to the decrease in the chitosan molecular weight (Abd El-Rehim et al., 2012).

Table 3: Calculated partial charge and electronegativity for the studied model molecules at the PM6 quantum mechanical semiempirical level of theory.

\begin{tabular}{|c|c|c|}
\hline Samples & Partial Charge & Electronegativity, Charge \\
\hline \multicolumn{3}{|l|}{ Chitosan } \\
\hline N1 & -0.016 & -0.321 \\
\hline $\mathrm{N} 2$ & -0.042 & -0.321 \\
\hline N3 & -0.034 & -0.321 \\
\hline \multicolumn{3}{|l|}{ Weak 1} \\
\hline N1 & -0.016 & -0.321 \\
\hline $\mathrm{N} 2$ & -0.042 & -0.321 \\
\hline N3 & 0.034 & -0.321 \\
\hline \multicolumn{3}{|l|}{ Weak 2} \\
\hline N1 & -0.016 & -0.321 \\
\hline $\mathrm{N} 2$ & -0.042 & -0.321 \\
\hline N3 & -0.034 & -0.321 \\
\hline \multicolumn{3}{|l|}{ Weak 3} \\
\hline N1 & -0.016 & -0.321 \\
\hline $\mathrm{N} 2$ & -0.042 & -0.321 \\
\hline N3 & -0.034 & -0.321 \\
\hline \multicolumn{3}{|l|}{ Weak 4} \\
\hline N1 & -0.016 & -0.321 \\
\hline $\mathrm{N} 2$ & -0.042 & -0.321 \\
\hline N3 & -0.034 & -0.321 \\
\hline \multicolumn{3}{|l|}{ Weak 5} \\
\hline N1 & -0.016 & -0.321 \\
\hline $\mathrm{N} 2$ & -0.042 & -0.321 \\
\hline N3 & -0.034 & -0.321 \\
\hline \multicolumn{3}{|l|}{ Weak 6} \\
\hline N1 & -0.016 & -0.321 \\
\hline N2 & -0.042 & -0.321 \\
\hline N3 & -0.034 & -0.321 \\
\hline \multicolumn{3}{|l|}{ Chitosan-1 } \\
\hline N1 & -0.125 & -0.246 \\
\hline $\mathrm{N} 2$ & -0.041 & -0.321 \\
\hline N3 & -0.033 & -0.321 \\
\hline
\end{tabular}

*Structures from W1 to W6 stand for Van der Waal interaction for up to 6 hydrogen bonds in the chitosan structure of three units. Cs-1 is the chitosan model molecule with removed hydrogen bonding.

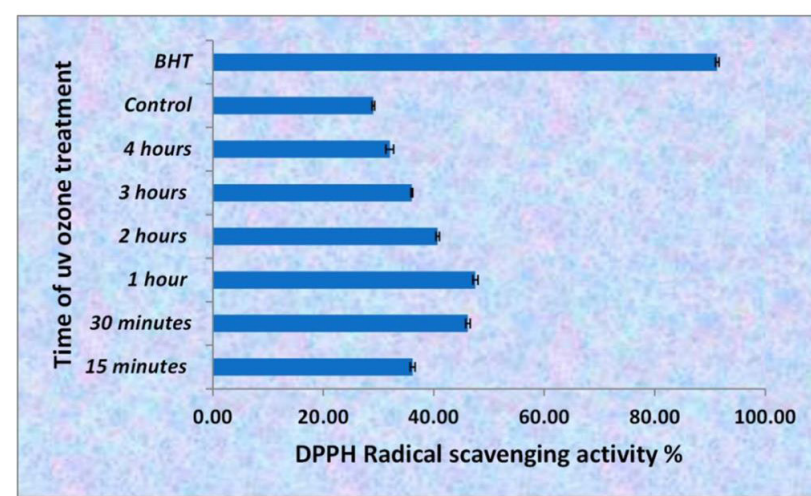

$5 A$
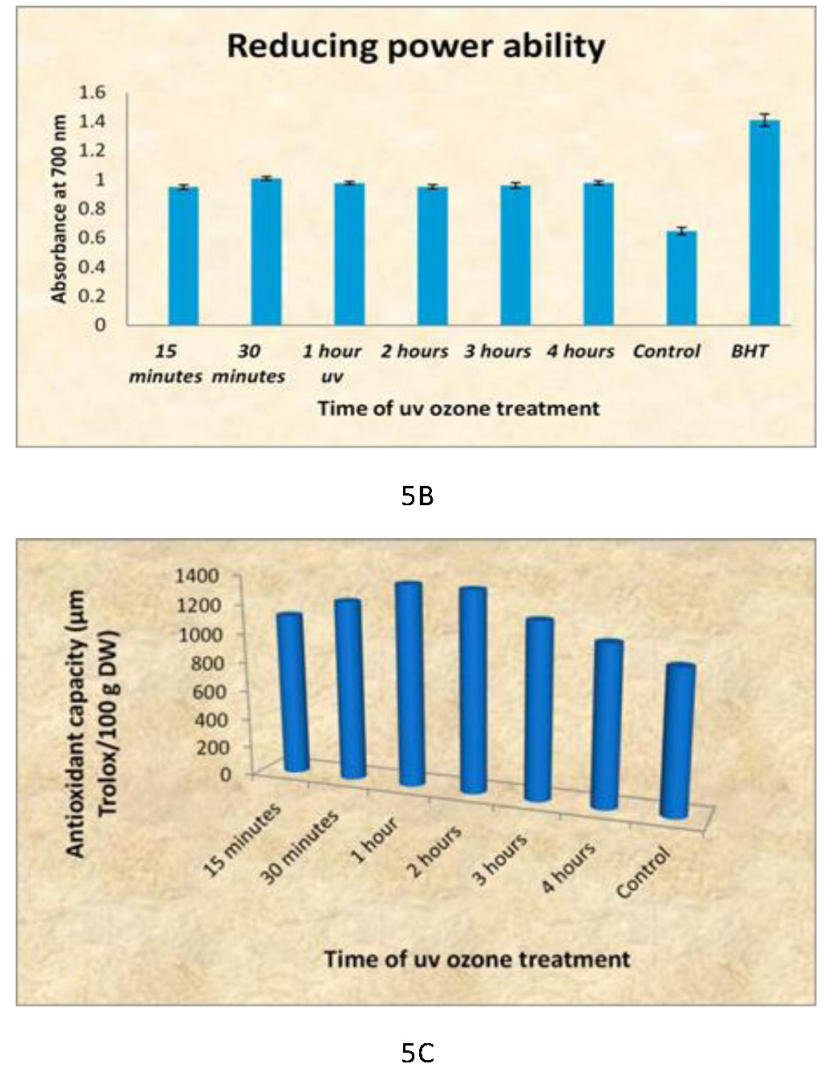

Fig. 5: Effect of UV ozone radiation on DPPH free-radical scavenging activity (A), on reducing power ability (B), ferric reducing antioxidant power (C) Data analysis was carried out with MICROSOFT EXCEL (2007). Data are means of triplicate experiments. Blank: Untreated chitosan.

\section{Effect of UV/ozone radiation on ferric reducing antioxidant power (FRAP)}

The mechanism of ferric reducing ion antioxidant power relies on the reduction of complex $\mathrm{Fe}^{3+}$-tripyridyltriazine to the $\mathrm{Fe}^{2+}$ form an antioxidant in acidic conditions, and color changes are seen, with a maximum absorption at $593 \mathrm{~nm}$ (Moon and Shibamoto, 2009). Fig. 5C obviously show that the ferric reducing power activity of the treated chitosan was similar to the results of the DPPH radical scavenging activity. UV/ozone with lower than $1 \mathrm{~h}$ radiation has no detectable effect on ferric reducing power. Chitosan after 1 and $2 \mathrm{~h}$ of UV/ozone exposure exhibited the 
highest ferric reducing power activity $(1376 \pm 15.18$ and $1365 \pm$ $21.79 \mu \mathrm{m}$ Trolox/100 g DW) respectively; which recorded about $30 \%, 29 \%$ increase in ferric reducing power activity respectively in comparison to untreated chitosan $(966 \pm 21.79 \mu \mathrm{m}$ Trolox $/ 100$ g DW). This result could be attributed to the difference in contents of hydroxyl and amino groups and different substituting groups.
The treatment of chitosan by radiation enhanced its chelating ability by increasing the functional groups as a result of oxidation reaction (Abd El-Rehim et al., 2012). Formerly, it was reported that at $2.5 \mathrm{mg} / \mathrm{mL}$, scavenging percentage of chitosan irradiated for $0,2,10,20 \mathrm{kGy}$ against hydroxyl radical was $16.6 \%, 41.1 \%$, $47.1 \%$ and $63.8 \%$, respectively (Feng et al., 2008).

Table 4: Antimicrobial testing on chitosan and its derivatives against different pathogenic microorganisms- Statistical analysis, Data analysis was carried out with MICROSOFT EXCEL (2007). Data are means of triplicate experiments.

\begin{tabular}{|c|c|c|c|c|c|c|c|c|c|}
\hline \multirow[b]{2}{*}{$\begin{array}{c}\text { Exposure } \\
\text { time (h) }\end{array}$} & \multicolumn{9}{|c|}{ Diameter of zone in (mm) } \\
\hline & $\begin{array}{c}\text { Candida } \\
\text { albicans } \\
\text { NRRLY4773 }\end{array}$ & $\begin{array}{c}\text { Candida } \\
\text { tropicalis }\end{array}$ & $\begin{array}{c}\text { Pseudomonas } \\
\text { aeroginosa } \\
\text { ATCC27953 }\end{array}$ & $\begin{array}{c}\text { E. coil } \\
\text { ATCC25922i }\end{array}$ & Bacillus cereus & $\begin{array}{c}\text { Staphylococcus } \\
\text { Aureus } \\
\text { ATCC29213 }\end{array}$ & $\begin{array}{c}\text { Bacillus } \\
\text { subtilis } \\
\text { ATCC6633 } \\
\end{array}$ & $\begin{array}{c}\text { Aspergillus } \\
\text { niger } \\
\text { Local isolate }\end{array}$ & Rhizopus \\
\hline 0 & $19 \pm 0.02$ & $19 \pm 0.05$ & - & $16 \pm 0.05$ & $16 \pm 0.01$ & $17 \pm 0.01$ & $16 \pm 0.04$ & $18 \pm 0.02$ & $19 \pm 0.02$ \\
\hline $1 / 4$ & $19 \pm 0.02$ & $19 \pm 0.01$ & $8 \pm 0.01$ & $17 \pm 0.04$ & $16 \pm 0.04$ & $17 \pm 0.04$ & $16 \pm 0.04$ & $18 \pm 0.04$ & $19 \pm 0.04$ \\
\hline $1 / 2$ & $19 \pm 0.01$ & $19 \pm 0.01$ & $13 \pm 0.03$ & $17 \pm 0.01$ & $17.2 \pm 0.01$ & $17 \pm 0.01$ & $17 \pm 0.02$ & $18 \pm 0.04$ & $19 \pm 0.01$ \\
\hline 1 & $19 \pm 0.03$ & $19 \pm 0.01$ & $16 \pm 0.01$ & $17 \pm 0.02$ & $18 \pm 0.03$ & $17 \pm 0.02$ & $18 \pm 0.01$ & $19 \pm 0.01$ & $20 \pm 0.02$ \\
\hline 2 & $20 \pm 0.01$ & $19 \pm 0.03$ & $18 \pm 0.02$ & $17 \pm 0.02$ & $19 \pm 0.01$ & $18 \pm 0.01$ & $18 \pm 0.03$ & $21 \pm 0.02$ & $21 \pm 0.01$ \\
\hline 3 & $21 \pm 0.02$ & $20 \pm 0.01$ & $21 \pm 0.02$ & $18 \pm 0.03$ & $19 \pm 0.01$ & $19 \pm 0.02$ & $19 \pm 0.03$ & $24 \pm 0.01$ & $23 \pm 0.01$ \\
\hline 4 & $25 \pm 0.01$ & $21 \pm 0.02$ & $22 \pm 0.02$ & $20 \pm 0.03$ & $20 \pm 0.01$ & $22 \pm 0.02$ & $21 \pm 0.01$ & $25 \pm 0.01$ & $26 \pm 0.03$ \\
\hline
\end{tabular}

\section{Anticoagulation and fibrinolytic activities}

The results showed promising anticoagulation activities for all samples at different concentrations (2000, 1000, 500 and $250 \mu \mathrm{g} / \mathrm{mL}$ ) (data not shown). Also, the results indicated that the highest exposure time (240 min.) was recorded by using untreated and treated samples by UV/ozone for $1 / 4$ hour at concentration ( 250 $\mu \mathrm{g} / \mathrm{mL}$ ), while the lowest exposure time (15 min) was reported by samples treated by UV/ozone for $1 / 2,1,2,3$ and $4 \mathrm{~h}$ at 250 $\mu \mathrm{g} / \mathrm{ml}$ concentrations. The anticoagulant activity is fundamentally attributed to the thrombin inhibition mediated by antithrombin and/or heparin cofactor II, with varied effectiveness's depending on the compound (Ciancia et al., 2010). Recently, it was reported in marine sulfated glycosaminoglycans as a promising anticoagulant agent (Pomin et al., 2015). As part of the interest in the present study, was the fibrinolytic activity evaluation for chitosan samples compared to standard fibrinolytic, Hemoclar drug (Pentosan sulfuric polyester, a product of Clin-Midy Paris). The results indicated that all samples have the same amount of standard "Hemoclar" preparation $(+4)$ except the chitosan treated UV/ozone for 3 and $4 \mathrm{~h}$. This sample had fibrinolytic activities equal $(+7)$ compared with standard "Hemoclar" preparation at a concentration of $2 \mathrm{mg} / \mathrm{mL}$. According to our knowledge, until now there is no report on chitosan as a fibrinolytic agent. All previous results recommended our products to be used in drug discovery.

\section{CONCLUSIONS}

This study focused in evaluating the effect of extracted chitosan and their UV/Ozone derivatives in different bioactivities as antimicrobial, antioxidant, anticoagulation and fibrinolytic activities. Through the work, the extracted chitosan was characterized and its property was studied. Although FTIR showed that chitosan UV/ozone exposure had a significant increase in bands intensity due to photooxidation. The molecular modeling at both B3LYP/6-31 g (d,p) and PM6 showed a change in the electronic properties of the irradiated chitosan. The radiation effect was supposed to affect the $\mathrm{H}$-bonding of the $\mathrm{NH}_{2}$ group through weak interaction with the 6-respective hydrogen bonding in the $3 \mathrm{NH}_{2}$ groups. The increase in DPPH radical scavenging activity and ferric reducing power upon irradiated chitosan with UV/ozone indicated the enhancement of their antioxidant activity property and suggested the possibility of using the UV/ozone irradiated chitosan as antioxidants that prevent flavor changes caused by lipid peroxidation. Also, UV/ozone revealed a promising antimicrobial and fibrinolytic in comparison to the native form. These results open a new trend to get chitosan derivatives to have potential multifunction properties.

\section{ACKNOWLEDGMENTS}

This work was supported by National Research Center [NRC], Chemistry of Natural and Microbial Research Departments, Prof. Dr. Osiris W. Guirguis, Biophysics Department, Faculty of Science, Cairo University.

\section{FINANCIAL SUPPORT AND SPONSORSHIP}

Nil.

\section{CONFLICT OF INTERESTS}

There are no conflicts of interest.

\section{REFERENCES}

Abd El-Rehim HA, El-Sawy NM, Hegazy el-SA, Soliman elSA, Elbarbary AM. Improvement of antioxidant activity of chitosan by chemical treatment and ionizing radiation. Int J Biol Macromol, 2012; 50(2):403-413.

Abdulkarim A, Isa MT, Abdulsalam S, Muhammad AJ, Ameh AO. Extraction and characterization of chitin and chitosan from mussel shell. Civil Environ Res, 2013; 3:108-114.

Ahlafi H, Moussout H, Boukhlifi F, Echetna M, Bennani MN, Slimane SM. Kinetics of N-Deacetylation of Chitin Extracted from Shrimp Shells Collected from Coastal Area of Morocco. Med J Chem, 2013; 2:503513 .

AOAC. 2005. Official Methods of Analysis $15^{\text {th }}$ Edition. Washington, DC: Association of Official Analytical Chemists.

Bano I, Afzal Ghauri M, Arshad MI, Yasin T, Younus M. Bioactivity of variant molecular weight chitosan against drug-resistant bacteria isolated from human wounds. Microb. Drug Resist, 2017; 23:958-965.

Benzie IFF, Strain JJ. The ferric reducing ability of plasma (FRAP) as a measure of antioxidant power, the FRAP assay. Anal Biochem, 1996; 239:70-76.

Brand-Williams W, Cuvelier ME, Berset C. Use of a free radical method to evaluate antioxidant activity. LWT-Food Sci Technol, 1995; 
28:25-30.

Ciancia M, Quintana I, Cerezo, AS. Overview of anticoagulant activity of sulfated polysaccharides from seaweeds in relation to their structures, focusing on those of green seaweeds. Curr Med Chem, 2010; $17: 2503-29$.

Feng T, Du Y, Li J, Hu Y, Kennedy JF. Enhancement of antioxidant activity of chitosan by irradiation. Carbohydr Polym, 2008; $73: 126-132$.

Ferrero F. Sustainable antimicrobial finishing of cotton fabrics by chitosan UV-grafting, from laboratory experiments to semi industrial scale-up. J Clean Prod, 2015; 96:244-252.

Gaussian 09, Revision C01, Frisch MJ, Trucks GW, Schlegel HB, Scuseria GE, Robb Staroverov MA, Keith T, Kobayashi R, Normand J, Raghavachari K, Rendell, A, Burant JC, Slyengar S, Tomasi J, Cossi M, Rega N, Millam JM, Klene M, Knox JE, Cross JB, Bakken V, Adamo C, Jaramillo J, Gomperts R, Stratmann RE, Yazyev O, Austin AJ, Cammi R, Pomelli C, Ochterski JW, Martin RL, Morokuma K, Zakrzewski VG, Voth GA, Salvador P, Dannenberg JJ, Dapprich S, Daniels AD, Farkas O, Foresman JB, Ortiz JV, Cioslowski J, Fox DJ, Gaussian, Inc, Wallingford C.T. 2010.

Gordon MF. 1990. The mechanism of antioxidant action. London: Elsevier Applied Science 1-18.

Guirguis O, El-Bassyouni GT, Esawy MA, Abd Elkader NR, Mahmoud HM, Mostafa HM, Abdel-Zaher NA. Exposure of chitosan to UV/ozone, Structural information and antibacterial activity. J Appl Pharm Sci, 2016; 6:124-130.

Heinz H, Suter UW. Atomic charges for classical simulations of polar systems. J Phys Chem B, 2004; 108:18341-18352.

Hongpattarakere T, Riyaphan O. Effect of deacetylation conditions on antimicrobial activity of chitosans prepared from carapace of black tiger shrimp (Penaeus monodon), Songklanakarin. J Sci Technol, 2008; 30(Supp 11):1-9.

Ibrahim M, Mahmoud AA. Computational notes on the reactivity of some functional groups. J Comput TheorNanosci, 2009; 6:1523-1526.

Kowalonek J. Studies of chitosan/pectin complexes exposed to UV radiation. Int J Biol Macromol, 2017a; 103:515-524.

Kowalonek J. Surface and thermal properties of UV-irradiated chitosan/poly (ethylene oxide) blends. J Photochem Photobiol A, 2017b; 348:209-218.

Lertsutthiwong P, How NC, Chandrkrachang S, Stevens WF. Effect of Chemical Treatment on the Characteristics of Shrimp Chitosan. J Met Mater Miner, 2002; 12:11-18.

Li Q, Dunn ET, Grandmaison EW, Goosen MFA. Applications and properties of chitosan. J Bioact Compat Pol, 1992; 7:370-397.

Lim C, Lee DW, Israelachvili JN, Jho YS, Hwang DS. Contact time- and $\mathrm{pH}$-dependent adhesion and cohesion of low molecular weight chitosan coated surfaces. Carbohydr Polym, 2015; 117:887-894.

Michael MN, El-Zaher NA, Ibrahim SF. Investigation into surface modification of some polymeric fabrics by UV/Ozone treatment. Polym Plast Tech \& Eng, 2004; 43:1041-1052.

Miehlich B, Savin A, Stoll H, Preuss H. Results obtained with the correlation energy density functional of Becke and Lee Yang and Parr. Chem Phys Lett, 1989; 157:200-206.

Moon JK, Shibamoto T. Antioxidant assays for plant and food components. J Agric Food Chem. 2009; 57:1655-1666.

Moreno-Vásqueza MJ, Valenzuela-Buitimeaa EL, PlascenciaJatomea M, Encinas-Encinas JC, Rodríguez-Félix F, Sánchez-Valdes S, RosasBurgos EC, Ocano-Higuera, VM, Graciano-Verdugoa AZ. Functionalization of chitosan by a free radical reaction, Characterization, antioxidant and antibacterial potential. Carbohydr Polym, 2017; 155:117-127.

Nawi MA, Sabar S, Jawad AH, Sheilatina, Wan Ngah WS. Adsorption of Reactive Red 4 by immobilized chitosan on glass plates: Towards the design of immobilized $\mathrm{TiO} 2$-chitosan synergistic photocatalystadsorption bilayer system. Biochem Eng J, 2010; 49:317-325.

Jawad AH, Nawi MA. Oxidation of crosslinked chitosanepichlorohydrine film and its application with $\mathrm{TiO}_{2}$ for phenol removal.
Carbohyd Polym, 2012; 90:87-94.

No HK, Lee MY. Isolation of Chitin from Crab Shell Waste. Journal Korean Soc. Food Nutrition, 1995; 24:105-113.

Oyaizu M. Studies on the product of browning reaction prepared from glucosamine. Japanese J Nutr, 1986; 44:307-315.

Pomin VH, Pinto MMM, de Sousa ME, da Silva MC. Marine Non-Glycosaminoglycan Sulfated Glycans as Potential Pharmaceuticals. Pharmaceuticals (Basel). 2015; 8:848-864.

Rashid TU, Rahman MM, Kabir S, Shamsuddin SM, Khan MA. A new approach for the preparation of chitosan from $\gamma$-irradiation of prawn shell, effects of radiation on the characteristics of chitosan. Poly Int, 2012 61:1302-1308.

Sionkowska A, Planecka A, Lewandowska K, Michalska M. The influence of UV-irradiation on thermal and mechanical properties of chitosan and silk fibroin mixtures. J Photoch Photobio B, 2014; 140:301-305.

Sionkowska A, Skopinska-Wisniewska J, Planecka A, Kozlowska J, The influence of UV irradiation on the properties of chitosan films containing keratin. Polym Degrad Stab, 2010; 95:2486-2491.

Srinivasa Reddy Ch, Ammani K, Rose Mary T. In vitro evaluation of fibrinolytic and antioxidant activities of Maba buxifolia (Rottb.) Juss Stem. J Pharmacogn Phytochem, 2015; 3:148-151.

Stewart JP, Mopac93, Fujitsu Ltd., Tokyo, Japan (Scigress Explorer v7.7.0.47), 2009.

Toan NV. Production of Chitin and Chitosan from Partially Autolyzed Shrimp Shell Materials. The Open Biomaterials Journal, 2009; 1:21-24.

US Pharmacopeia of the United State of America $16^{\text {th }}$ Revision, Mack Publishing Company, Washington, DC USA, 1960:317.

Ushakumari UN, Ramanujan R. Astaxanthin from shrimp shell waste. Int J Pharm Chem Res, 2012; 1:1-6.

Wang T, Turhan M, Gunasekaran S. Selected properties of $\mathrm{pH}$ sensitive, biodegradable chitosan- poly (vinyl alcohol) hydrogel. Polym Int, 2004; 53:911-918.

Wang W, Bo SQ, Li SQ, Qin W. Determination of the MarkHouwink equation for chitosans with different degrees of deacetylation. Int J Biol Macromol, 1991; 13:281-285.

Wassel MA, Farag RS, Shehata HA, Anwar MM, Mohamed HA. Investigate the Adsorption Mechanism of Heavy Metals as Chromium Ions $\left(\mathrm{Cr}^{+3}\right)$ from Different Solutions Using Modified Chitosan Egypt. J Chem. The $8^{\text {th }}$. Int Conf Text Res Div, Nat Res Centre, Cairo, 2017; 1-14.

William BJ. Electronegativity from Avogadro to Pauling, Part 1, Origins of the Electronegativity Concept. J Chem Educ, 1996; 73:11-20.

You L, Lu F, Li D, Qiao Z, Yin Y. Preparation and flocculation properties of cationic starch/chitosan crosslinking-copolymer. J Hazard Mater, 2009; 172:38-45.

Zajạc A, Hanuza J, Wandas M, Dymin'ska L. Determination of $\mathrm{N}$-acetylation degree in chitosan using Raman spectroscopy. Spectrochim Acta A, 2015; 134:114-120.

Zainal Z, Hui LK, Hussein MZ, Abdullah AH, Hamadneh IR. Characterization of $\mathrm{TiO}_{2}-$ Chitosan/Glass photocatalyst for the removal of a monoazo dye via photodegradation-adsorption process J Hazard Mater, $2009 ; 164: 138-145$.

Zhang D, Yang S, Chen Y, Liu S, Zhao H, Gu J. ${ }^{60} \mathrm{Co} \gamma$-ray Irradiation Crosslinking of Chitosan/Graphene Oxide Composite Film Swelling, Thermal Stability, Mechanical, and Antibacterial Properties Polymers, 2018; 10:294. doi: 10.3390/polym10030294.

Becke AD. Density-functional thermochemistry. III. The role of exact exchange. J Chem Phys, 1993; 98:5648-52.

How to cite this article:

Ragab T, El-Bassyouni GT, Helmy W, Taie H, Refaat A, Ibrahim MA, Abd El-Hmeed E, Esawy MA. Evaluation of Multifunction Bioactivities of Extracted Chitosan and their UV/Ozone Derivatives. J App Pharm Sci, 2018; 8(10): 053-062. 